\title{
Hypertension, diabetes mellitus, overweight and obesity in employees under health transition at the railways company in Congo-Brazzaville
}

\author{
Bertrand Fikahem Ellenga Mbolla ${ }^{1,2 *}$, Thierry Raoul Alexis Gombet ${ }^{2}$, Henri Germain Monabeka ${ }^{2}$, \\ Paul Macaire Ossou-Nguiet ${ }^{2}$, Solange Flore Mongo-Ngamami ${ }^{1}$, Christian Michel Kouala Landa ${ }^{1}$, \\ Suzy-Gisèle Kimbally-Kaky ${ }^{1,2}$, Benjamin Longo-Mbenza ${ }^{3}$
}

\footnotetext{
${ }^{1}$ Department of Cardiology, University Hospital of Brazzaville, Brazzaville, Congo

${ }^{2}$ Department of Medicine, Faculty of Health Sciences, Marien Ngouabi University, Brazzaville, Congo

${ }^{3}$ Faculty of Health Sciences, Walter Sisulu University, Mthatha, South Africa

Email: *ellenga bertrand@hotmail.com
}

Received 25 October 2013; revised 6 December 2013; accepted 16 December 2013

Copyright (C) 2014 Bertrand Fikahem Ellenga Mbolla et al. This is an open access article distributed under the Creative Commons Attribution License, which permits unrestricted use, distribution, and reproduction in any medium, provided the original work is properly cited. In accordance of the Creative Commons Attribution License all Copyrights (C 2014 are reserved for SCIRP and the owner of the intellectual property Bertrand Fikahem Ellenga Mbolla et al. All Copyright (C) 2014 are guarded by law and by SCIRP as a guardian.

\section{ABSTRACT}

Background and Aim: Cardiovascular risk (CVR) factors, namely hypertension (HT), diabetes mellitus and obesity, are a public health problem in sub-Saharan Africa because of health transition. The additional effect of the social gradient within the railway companies in Congo-Brazzaville on high CVR is not yet established. The aim of this study was to determine the extent of hypertension, diabetes mellitus, overweight, and obesity and to identify the contributing factors of fatness and hypertension. Methods: This was a cross-sectional study conducted in April 2013. A simple random sample of 255 out of all 2550 workers from the railway companies of Congo was examined for epidemiological, clinical and biological variables. Results: Out of the study sample, 231 (90.6\%), 79 (31\%), and $52(20.4 \%)$ were men, rural dwellers, and senior executives, respectively. The mean age was $45 \pm 13$ years (range 19 to 63 years). The rates of overweight, hypertension, obesity, and diabetes mellitus were $40.3 \%(n=103), 29.4 \%(n=75)$, $7.5 \%(n=19)$, and $3.5 \%(n=9)$, respectively. In univariate analysis, female sex (OR 2.7, 95\% CI 1.13 6.45, $\mathrm{p}=0.01$ ), senior executive (OR 2.4; 95\% CI: 1.3 4.5; $p=0.003$ ) and physical inactivity (OR 2.5; 95\% CI: 1.5 - 4.2; $p<0.001)$ were significantly associated with overweight. Female sex (OR 7.5, 95\% CI: 2.6 $21 ; p<0.001$ ) and senior executive (OR 3.17; 95\% CI:

*Corresponding author.
1.2 - 8.3) were also significantly associated with obesity. In logistic regression, overweight $(\mathrm{OR}=4.8,95 \%$ CI $2.8-11, \mathrm{p}<0.0001)$, and obesity $(\mathrm{OR}=6.8,95 \% \mathrm{CI}$ $2.1-22, p=0.01)$ were identified as the most important and independent determinants of hypertension. Conclusions: Fatness is emerging and it is the most contributing factor of hypertension among workers at the Congolese railway companies. There is also a significant interaction between non-modifiable factors (genetic: females and family history) and modifiable factors (inactivity, fatness) for higher risk of hypertension. Health promotion should be emphasized by physical activity programs.

\section{KEYWORDS}

Hypertension; Diabetes Mellitus; Overweight; Obesity; Workplace; Congo; Sub-Saharan Africa

\section{INTRODUCTION}

The cardiovascular risk factors (CVRF), namely hypertension, diabetes mellitus and fatness (overweight/obesity) are a public health problem because of the high morbidity and mortality worldwide and in the developing countries, including sub-Saharan Africa (SSA) [1,2]. People are facing health (demographic, epidemiologic, and nutrition) transitions which may explain an important cardiovascular disease (CVD)-associated mortality [2]. Globally, diabetes mellitus has contributed to $6 \%$ of all deaths in 2010 [3], while hypertension is considered as the 
leading cause of the disease burden [4]. The prevalence of hypertension in SSA varies from $13.7 \%$ in rural areas to $20.7 \%$ in urban areas [5], and that of diabetes mellitus varies between $3 \%$ and $14.5 \%$ [3]. Moreover, the incidence of CVRF will increase with high rates of mortality in the upcoming decades $[1,2,5,6]$. Therefore, World Health Organization (WHO) has recommended active primary prevention and control of CVRF and CVD in countries with limited resources [7]. This prevention includes hypertension, smoking, physical inactivity and obesity $[7,8]$. The lack of primordial prevention of CVRF has already been a concern among general and inactive working pompulations from Congo Brazzaville [9-12]. Indeed, according to Kimbally-kaky et al., the prevalence was 32\% for hypertension, $7.1 \%$ for diabetes and $12 \%$ for obesity in urban population from Brazzaville [9]. Higher frequencies were reported by Levisse et al., $45 \%$ for hypertension, $12 \%$ for diabetes and $25 \%$ for obesity during a second screening in the community of Congo [10]. Gombet $e t$ al. highlighted the importance of the cardiometabolic risk among Bank sedentary employees from Brazzaville [11,12]. The additional effect of social gradient within the railway companies in Congo Brazzaville on high CVR is not yet established. The aim of this study was to determine the extent of hypertension, diabetes mellitus, overweight, and obesity and to identify the contributing factors of fatness and hypertension.

\section{MATERIALS AND METHODS}

This was a cross-sectional survey conducted from 1st to 22 April 2013 at the occupational medicine centers of the railways company in urban and rural areas of Brazzaville (capital) and Pointe-Noire (port), cities separated by 510 $\mathrm{km}$ of railways, on the occasion of the annual systematic review recommended by law.

Study population: A simple random sample of 255 out of all 2550 workers from the railways company of Congo was examined for epidemiological, clinical and biological variables. The criteria of exclusion were fever, infections, chronic diseases, pregnancy, and refusal for participation to the study. Data were collected on a pre-coded structured and standardized questionnaire using self-reported languages such as French, Lingala and Kituba. The consent of the management and staff was obtained. The approval of the Ethics Committee of the Faculty of Health Sciences, Brazzaville, Congo, was granted. Thus, the study was carried out according to the Helsinki Declaration.

Data collection: Epidemiological data comprised of sex, age, geographic area (rural or urban), occupational status (senior executive or no), family history of diabetes and hypertension, addictions (alcohol and tobacco), physical inactivity (yes or no), and regular consumption of fruits and vegetables. Clinical examination recorded weight (kg) using a mechanical scale (GIMA, Milano, Italy) with an accuracy of $0.1 \mathrm{~kg}$, and height (m) with a standard stadiometer. Body mass index (BMI) was weight in $\mathrm{kg}$ divided by (height) $\times$ (height). Blood pressure was taken after a rest of at least 15 minutes, by averaging 3 shots. Systolic blood pressure (SBP) and diastolic blood pressure (DBP) were measured using automatic and validated OMRON M6 Comfort device (HEM-7221-E OMRON Healthcare Co., Ltd.., Kyoto, Japan). The fasting plasma glucose $(\mathrm{g} / \mathrm{L})$ was assayed after venipuncture and overnight 8 to 12 hours using an autoanalyzer and Biomerieux kits (Biomerieux, Mercy l'Etoile, France).

Definitions: Obesity was defined by BMI $\geq 30 \mathrm{~kg} / \mathrm{m}^{2}$ and overweight by BMI between 25 and $29.9 \mathrm{~kg} / \mathrm{m}^{2}$. Hypertension was defined by SBP $\geq 140 \mathrm{~mm} \mathrm{Hg}$ and DBP $\geq 90 \mathrm{mmHg}$ or long-term antihypertensive medication. Diabetes was defined by fasting glucose $\geq 1.26 \mathrm{~g} / \mathrm{L}$ or long-term medication for diabetes. Physical inactivity, current smoking and excessive alcohol intake (EAI) were defined according to the criteria used by Gombet et al. [11]. Regular consumption of fruit and vegetables (ReFrVe) was reported by recall of the previous week of this survey.

Statistical analysis: Data were expressed in proportions for categorical variables and mean \pm standard deviation for continuous variables. In univariate analysis, Student t-test, Chi-square test, and Odds ratio (OR with 95\% Confidence Interval or CI) were used for comparisons of means and proportions, and associations, respectively. In multivariate analysis, after adjusting for confounding factors, logistic regression model identified independent determinants of hypertension, overweight and obesity. The criterion for statistical significance was pvalue $<0.05$. All analyses were performed using SPSS software version 10.0 for Windows (SPSS Inc, Chicago, IL, USA).

\section{RESULTS}

There were 231 men (90.6\%) and 24 women (9.4\%). The mean age was $45 \pm 13$ years (range 19 and 63 years). Among them, 79 lived in rural areas (31\%) and 52 were senior executives (20.4\%). Other epidemiological characteristics are reported in Table 1 . Table 2 presents the characteristics of the clinical variables in this population. The prevalence of overweight was $40.3 \%(n=103)$. The univariate factors associated with overweight were female sex, and being senior executive (Table 3 ). Obesity was noted in 19 cases (7.5\%). The female sex, urban residence and executive position were significantly associated with obesity (Table 3). The frequency of diabetes was 3.5\% (95\% CI 1.6 - 6.6) or 9 cases. The frequency of hypertension was $29.4 \%$ (95\% CI 23.9 - 35.4) or 75 cases. In univariate analysis, family history of hypertension, senior position, overweight, obesity, and diabetes 
Table 1. General characteristics of all participants.

\begin{tabular}{cc}
\hline & $\mathrm{n}(\%)$ \\
\hline Female sex & $24(9.4)$ \\
Senior executive & $52(20.4)$ \\
Rural area & $79(31)$ \\
Excessive alcohol intake & $177(69.7)$ \\
Current smoking & $43(16.9)$ \\
Diabetes in parents & $26(10.2)$ \\
Hypertension in parents & $41(16.1)$ \\
ReFrVe & $192(75.3)$ \\
Physical inactivity & $100(39.2)$ \\
\hline
\end{tabular}

${ }^{*}$ ReFrVe: Regular consumption of fruit and vegetables.
Table 2. Clinicals and biologicals variables of population.

\begin{tabular}{cc}
\hline & Means \pm standard deviation (range) \\
\hline Age (years) & $45 \pm 13(19-63)$ \\
weight (Kg) & $74.2 \pm 9.6(56-114)$ \\
Height (cm) & $172.5 \pm 5(158-195)$ \\
BMI (Kg/m $\left.{ }^{2}\right)$ & $24.8 \pm 3(19-38)$ \\
SBP (mm Hg) & $133.3 \pm 22.2(90-213)$ \\
DBP (mm Hg) & $84.7 \pm 12.4(61-127)$ \\
Glycaemia (g/dL) & $104.3 \pm 22.4(75-218)$ \\
\hline
\end{tabular}

BMI: Body mass index; SBP: Systolic blood pressure; DBP: Diastolic blood pressure.

Table 3. Univariates Odds of overweight and obesity.

\begin{tabular}{|c|c|c|c|c|c|c|c|c|}
\hline & \multicolumn{4}{|c|}{ Overweight $(\mathrm{n}=103)$} & \multicolumn{4}{|c|}{ Obesity $(n=19)$} \\
\hline & n (\%) & OR & IC $95 \%$ & p-value & n (\%) & OR & IC 95\% & p-value \\
\hline Female sex & $15(14.6)$ & 2.7 & $1.13-6.45$ & 0.018 & $7(36.8)$ & 7.5 & $2.6-21.5$ & $<0.001$ \\
\hline EAI & $68(66)$ & 0.7 & $0.4-1.2$ & 0.18 & $14(73.7)$ & 1.23 & $0.42-3.56$ & 0.45 \\
\hline Current smoking & $18(17.5)$ & 1.07 & $0.5-2.1$ & 0.47 & $4(21.1)$ & 1.34 & $0.42-4.27$ & 0.30 \\
\hline Diabetes in parents & $13(12.6)$ & 1.54 & $0.68-3.48$ & 0.19 & $2(10.5)$ & 1.03 & $0.22-4.77$ & 0.45 \\
\hline HTIP & $20(19.4)$ & 1.5 & $0.76-2.94$ & 0.15 & $6(31.6)$ & 2.65 & $0.94-7.42$ & 0.06 \\
\hline Senior executive & $30(29.1)$ & 2.42 & $1.3-4.51$ & 0.003 & $8(42.1)$ & 3.17 & $1.2-8.3$ & 0.02 \\
\hline Rural area & $19(25.3)$ & 0.6 & $0.3-1.2$ & 0.13 & $2(10.5)$ & 0.24 & $0.03-0.94$ & 0.02 \\
\hline Physical inactivity & $54(52.4)$ & 2.5 & $1.51-4.26$ & $<0.001$ & $10(52.6)$ & 1.8 & $0.7-4.6$ & 0.15 \\
\hline Diabetes & $6(5.8)$ & 3 & $0.75-12.5$ & 0.09 & $1(5.3)$ & 1.53 & $0.18-13.3$ & 0.32 \\
\hline
\end{tabular}

EAI: excessive alcohol intake; HTIP: hypertension in parents; ReFrVe: Regular consumption of fruit and vegetables.

mellitus were significantly associated with hypertension (Table 4). In logistic regression, the independent determinants of hypertension were overweight and obesity (Table 5).

\section{DISCUSSION}

This study allowed us to determine the CVRF in workers from the railways company of Congo. The magnitude of overweight and hypertension and the emerging of diabetes and obesity with significant interrelations between CVRF were demonstrated among these Congolese workers.

Epidemiological aspects: There was a male predominance (90.6\%) as heavy working is not suitable in the railways Company. In fact, women are often underrepresented in most studies of CVRF at SSA workplace [11-14]. We found a high rate of addiction among railway workers, with $16.9 \%$ for smoking and $69.7 \%$ for excessive alcohol consumption. Other authors in SSA report discrepancies about addiction rates: $73 \%$ for excessive alcohol consumption, 23\% of smoking in Cameroon [14], 12.3\% of smoking in Senegal [15], 33.6\% of excessive alcohol consumption and $32 \%$ of smoking in Congo. [11] These differences appear to be related to the type of work performed, cultural beliefs such as religion (Muslim and protestant), Bantu taboos and traditions in developing countries, and the environment influence (degree of urbanization, globalization and social inequalities). However, the frequency of physical inactivity that we found (39.2\%) is less than that of Gombet et al. (70\%) in the workplace in Brazzaville [11], and Mbaye et al. (68\%) among postal workers in Senegal [15]. Indeed, this difference appears to be related to the working conditions of each other. The bank and post office men then appear more sedentary than the railroad workers. It is recognized that physical inactivity is among major causes of obesity and glucose disorders in black Africans [16].

Overweight and obesity: Overweight was reported in $47.8 \%$ vs. $7.5 \%$ for obesity in this study. In the general population in Brazzaville, the prevalence of obesity is $8.6 \%$ vs. $18.5 \%$ of overweight according to Kimballykaky et al [9]. Levisse et al. Report higher prevalence of obesity and estimated $20 \%$ using a screening in a Congolese community [10]. This difference is related to study designs [10]. However, Gombet et al. were found among bank employees in Brazzaville a BMI $\geq 25$ in $65.1 \%$ of cases. Indeed, it is for most office workers, so physical inactivity. Furthermore, the epidemic proportion of $65.1 \%$ of overweight among Bank employees in Brazzaville [11] explained by the strong link between physical inactivity and obesity in the literature [16]. This study confirmed positive associations between overweight and physical inactivity. Globally, obesity affects more women [7], and its prevalence in SSA is up to $60 \%$ in some African regions [17]. It should be noted that obesity rates currently found in SSA, are comparable to those found in developed countries $[18,19]$. Similarly, the role 
Table 4. Univariate Odds of hypertension.

\begin{tabular}{ccccc}
\hline & \multicolumn{3}{c}{ Hypertension (n= 75) } \\
\hline & $\mathrm{n}(\%)$ & OR & $95 \%$ IC & p-value \\
\hline Female sex & $10(13.3)$ & 1.82 & $0.7-4.3$ & 0.12 \\
Excessive alcohol intake & $51(68)$ & 0.89 & $0.49-1.59$ & 0.4 \\
Current smoking & $15(20)$ & 1.35 & $0.67-2.71$ & 0.24 \\
HTIP & $19(25.9)$ & 2.43 & $1.2-4.8$ & 0.009 \\
Diabetes in parents & $8(10.7)$ & 1.1 & $0.44-2.6$ & 0.51 \\
Senior executive & $27(36)$ & 3.48 & $1.8-6.5$ & 0.0001 \\
ReFrVe & $61(81.3)$ & $0.83-3.1$ & 0.09 \\
Rural area & $19(25.3)$ & $0.37-1.24$ & 0.13 \\
Overweight & $48(64)$ & 3.7 & $2.2-7.1$ & $<0.00001$ \\
Obesity & $11(14.7)$ & $1.5-9.6$ & 0.006 \\
Physical inactivity & $35(46.7)$ & 5.1 & $0.89-2.6$ & 0.07 \\
Diabetes mellitus & $6(8)$ & 5.1 & 0.01 \\
\hline
\end{tabular}

HTIP: hypertension in parents; ReFrVe: Regular consumption of fruit and vegetables.

Table 5. Independants determinants of overweight, obesity and hypertension by logistic regression.

\begin{tabular}{|c|c|c|c|c|c|c|}
\hline & Independant determinants & $\beta$ coefficient & Standard error & $\chi^{2}$ & OR(95\% CI) & $\mathrm{p}$-value \\
\hline \multirow{2}{*}{ Overweight } & Hypertension (yes vs no) & 1.315 & 0.317 & 4.147 & $3.72(2-6.93)$ & $<0.0001$ \\
\hline & Physical inactivity (yes vs no) & 0.736 & 0.312 & 2.354 & $2.08(1.13-3.85)$ & 0.018 \\
\hline Obesity & Sexe (male vs female) & -2.816 & 0.91 & -3.091 & $0.05(0.01-0.35)$ & 0.002 \\
\hline \multirow{2}{*}{ Hypertension } & Obesity (yes vs no) & 1.929 & 0.604 & 3.189 & $6.88(2.1-22.5)$ & 0.001 \\
\hline & Overweight (yes vs no) & 1.738 & 0.356 & 4.874 & $5.69(2.82-11.4)$ & $<0.0001$ \\
\hline
\end{tabular}

of overweight and obesity on the increase in cardiovascular risk, with a significant impact on morbidity and mortality is well established [4,7].

Diabetes: The present prevalence of diabetes (3.5\%) among both rural and urban workers was lower than those observed in urban areas by Kimbally-kaky et al. (7\%) [9] and Levisse et al. (13\%) [10] in the general population, and Gombet et al. (7.9\%) in a Bank setting [11]. Overall, these trends meet the range of diabetes prevalence in SSA according to Mbanya et al. [3]. In the African environment, Mbanya et al. showed that lack of exercise is the most important origin of overweight and diabetes [3].

Hypertension: Hypertension was the second CVRF (29.4\%) in our study, after overweight. Associated factors in univariate analysis were family history of hypertension, high socio-professional status, overweight and diabetes. The independent determinants of hypertension were only overweight and obesity. This prevalence is comparable to those reported in the general population in Brazzaville [9], or in other SSA countries [5,17,20]. The prevalence of hypertension in rural areas is lower than in SSA cities $[3,5,8,17]$. At the workplace, the prevalence of hypertension varies from $29.7 \%$ among officials in Abidjan (Ivory Coast) [13] to $43.7 \%$ among postal workers in Saint-Louis (Senegal) [15]. These differences can be explained by the environment, lifestyle, metabolic disorders and genetic characteristics $[7,8,11]$.

The link between family history of hypertension, stress and hypertension at workplace is known [21]. In addition, the increase of body weight is well correlated with the increase of blood pressure [17]. With the obesity pan- demic worldwide and in SSA in particular [7,19], effective prevention and control of contributing factors and metabolic consequences are urgently needed among these railway men [18,22-24].

\section{CONCLUSION}

Fatness is emerging and it is the most contributing factor of hypertension among these Congolese workers at the railway companies. There is also a significant interaction between non-modifiable factors (genetic: females and family history) and modifiable factors (inactivity, fatness) for higher risk of hypertension. Physical activity programs should emphasize health promotion.

\section{ACKNOWLEDGEMENTS}

The authors thank the management of CFCO for covering the costs of the campaign. Also, we thank Mr. Emmanuel KOMA and Dr. François LEKAKA (Centre Médico-Social du CFCO) for facilitating the completion of this work.

\section{REFERENCES}

[1] Araújo, F., Gouvinhas, C., Fontes, F., La Vecchia, C., Azevedo, A. and Lunet, N. (2013) Trends in cardiovascular diseases and cancer mortality in 45 countries from five continents (1980-2010). European Journal of Preventive Cardiology. http://dx.doi.org/10.1177/2047487313497864

[2] Rapport sur la Santé dans le Monde 2013. (2013) La recherche pour la couverture sanitaire universelle. OMS, 79. http//apps.who.int/iris/bitstream/10665/85764/1/9789240 
691193 fre.pdf

[3] Mbanya, J.C., Motala, A.A., Sobngwi, E., Assah, F.K. and Enoru, S.T. (2010) Diabetes in sub-Saharan Africa. Lancet, 375, 2254-2266. http://dx.doi.org/10.1016/S0140-6736(10)60550-8

[4] Lim, S.S., Vos, T., Flaxman, A.D., Danaei, G., Shibuya K., Adair-Rohani, H., AlMazroa, M.A., Amann, M., Ross Anderson, H., Andrews, K.G., Aryee, M., Atkinson, C., et al. (2012) A comparative risk assessment to 67 risk factors and risk factor clusters in 21 regions, 1999-2010: A systematic analysis for the Global Burden of Disease Study. Lancet, 380, 2224-2260.

http://dx.doi.org/10.1016/S0140-6736(12)61766-8

[5] Twagirumukiza, M., De Backar, C., Kips, J.G., de Backer, G., Vander Stichele, R. and Van Bortel L.M. (2011) Current and projected prevalence of arterial hypertension in sub-Saharan africa by sex, age and habitat: An estimate from population studies. Journal of Hypertension, 29, 1243-1252.

http://dx.doi.org/10.1097/HJH.0b013e328346995d

[6] Danaei, G., Finucane, M.M., Lu, Y., Singh, G.M., Cowan, M.J., Paciorek, C.J., Lin, J.K.,, Farzadfar, F., et al. (2011) National, regional, and global trends in fasting plasma glucose and diabetes prevalence since 1980: Sytematic analysis of health examination surveys and epidemiological studies with 370 country-years and 2.7 million participants. Lancet, 378, 31-40.

http://dx.doi.org/10.1016/S0140-6736(11)60679-X

[7] Rapport sur la Situation Mondiale des Maladies Non Transmissibles en 2010 (2011) Résumé d'Orientation. OMS 2011, ISBN 978924156422 9, 38-45.

www.who.int/nmh/publications/ncd report-summary fr.p df

[8] Ibrahim, M.M. and Damasceno, A. (2012) Hypertension in developing countries. Lancet, 380, 611-619. http://dx.doi.org/10.1016/S0140-6736(12)60861-7

[9] Kimbally-Kaky, G. (2004) Hypertension artérielle et les autres facteurs de risque cardiovasculaires à Brazzaville. Ministère de la santé et de la population-OMS. Rapport d'enquête. Brazzaville. http//www.who.int/entity/chp/steps/STEPS_Congo_Data. pdf

[10] Levisse, P., Mughnetsyan, V. and Kessy, G.S. (2009) Epidemiological study based on mass screening for diabetes, hypertension and android obesity in Brazzaville (Congo), 2008. Médecine et Maladies Métaboliques, 3, 438-441. http://dx.doi.org/10.1016/S1957-2557(09)72413-7

[11] Gombet, T., Longo-Mbenza, B., Ellenga Mbolla, B., Ikama, M.S., Mokondjimobe, E. and Nkoua, J.L. (2012) Aging, female sex, migration, elevated HDL-C and inflammation are associated with prevalence of metabolic syndrome among African bank employees. International Journal of General Medecine, 5, 495-503.

[12] Gombet, Th., Kimbally-Kaky, G., Ikama, M.S. and Ellenga Mbolla, B.F. (2007) Hypertension artérielle et autres facteurs de risque cardiovasculaires en milieu professionnel Brazzavillois. Médecine d'Afrique Noire, 54, 545-548.

[13] Koffi, N.M., Sally, S.J., Kouame, P., Silue, K. and Nama,
A.J. (2001) Facies de l’hypertension artérielle en milieu professionnel à Abidjan. Médecine d'Afrique Noire, 48, 257-260.

[14] Bita Fouda, A.A., Lemogoum, D., Owona Manga, J., Dissongo, J., Tobbit, R., Ngounou Moyo, D.F., Etapelong Sume, G. and Kollo, B. (2012) Epidemiologie de l'obésité en milieu du travail à Douala, Cameroun. Revue Médicale de Bruxelles, 33, 131-137

[15] Mbaye, A., Ndiaye, M.B., Kane, A.D., Ndoume, F., Diop, S., Yaméogo, N.V. and Kane, A. (2011) Screening of cardiovascular risk factors among workers of a private telecommunication company in Senegal. Archives de Maladies Professionnelles et de l'Environnement, 72, 96-99. http://dx.doi.org/10.1016/j.admp.2010.10.001

[16] Assah, F.K., Ekelund, U., Brage, S., Mbanya, J.C. and Wareham, N.J. (2011) Urbanization, physical activity, and metabolic health in sub-Saharan Africa. Diabetes Care, 34, 491-496. http://dx.doi.org/10.2337/dc10-0990

[17] Cappuccio, F.P., Kerry, S.M., Adeyemo, A., Luke, A., Amoah, A.G., Bovet, P., Connor, M.D., Forrester, T., Gervasoni, J.P., Kimbally Kaki, G, Plange-Rhule, J., Thorogood, M. and Cooper, R.S. (2008) Body size and blood pressure. An analysis of Africans and the African diaspora. Epidemiology, 19. 38-46. http://dx.doi.org/10.1097/EDE.0b013e31815c4d2c

[18] Mina, R. and Casolin, A. (2007) National standard for health assessment of rail workers: The first year. Medical Journal of Australia, 187, 394-397.

[19] Finucane, M.M., Stevens, G.A., Cowan, M.J., Danaie, G., Lin, J.K., Paciorek, C., Sing, G.M., et al. (2011) National, regional, and global trends in body-mass index since 1980: Systematic analysis of health examination surveys and epidemiological studies with 960 country-years and 9.1 milion participants. Lancet, 377, 557-567. http://dx.doi.org/10.1016/S0140-6736(10)62037-5

[20] Yayehd, K., Damorou, F., Akakpo, R., Tchérou, T., N’da, N.W., Pessinaba, S., Belle, L. and Johnson, A. (2013) Prevalence and determinants of hypertension in Lomé (Togo): Results of a screening in May 2011. Annales de Cardiologie et d'Angeiologie, 62, 43-50. http://dx.doi.org/10.1016/j.ancard.2012.09.006

[21] Harada, K., Karube, Y., Saruhara, H., Takeda, K. and Kuwajima, I. (2006) Workplace hypertension is associated with obesity and family history of hypertension. $\mathrm{Hy}$ pertension Research, 29, 969-976. http://dx.doi.org/10.1291/hypres.29.969

[22] Mina, R. and Casolin, A. (2012) The australian standard for rail workers five years on. Occupationnal Medecine, 62, 642-647. http://dx.doi.org/10.1093/occmed/kqs170

[23] Ng, K.L., Quinn, S., Gill, T.K., Hill, C. and Shanahan, E.M. (2013) Impact of the new national health standard for rail safety workers on ischaemic heart disease risk factors in train drivers. Internal Medicine Journal, 43, 650-655. http://dx.doi.org/10.1111/j.1445-5994.2012.02923.x

[24] Ghiasvand, M., Heshmat, R., Golpira, R., Haghpanah, V., Soleimani, A., Shoushtarizadeh, P., Tavangar, S.M. and Larijani, B. (2006) Shift working and risk of lipid disorders: A cross-sectional study. Lipids Health Diseases, 5, 9. http://dx.doi.org/10.1186/1476-511X-5-9 